\title{
Financial Buyers in Takeovers: Focus on Cost Efficiency
}

\author{
Halina Frydman ${ }^{*}$, Roman Frydman**, Susanne Trimbath***
}

\begin{abstract}
This paper examines whether financial buyers are more likely to initiate takeovers of inefficient firms. We show that they indeed are and thus conclude that takeovers by financial buyers play a potentially beneficial role in the allocation of corporate assets in the U.S. economy. Our analysis of determinants of takeovers initiated by financial buyers uses an application of the methodology developed in Trimbath, Frydman and Frydman (2001). In order to illustrate efficiency enhancements introduced by financial buyers, we select Forstmann and Little's acquisition of General Instrument for a brief case study. We show that their aggressive programs of cost management substantially improved the efficiency of General Instrument. Moreover, it allowed General Instrument to expand research and development to become the global leader in high definition television.
\end{abstract}

JEL Keywords: G24 - Investment Banking; G3 - Corporate Finance and Governance; G34 - Mergers, Acquisitions; C2 - Econometric Methods

Acknowledgements: The authors wish to thank James R. Barth for helpful comments and encouragement in the writing of this paper; and Kay Ma for her assistance and patience in updating the data set. Roman Frydman would like to thank the C.V. Starr Center for Applied Economics at New York University for support during the preparation of this paper.

*Stern School of Business, New York University, **Department of Economics, New York University, and ***Milken Institute. Direct correspondence to: Susanne Trimbath, Research Economist; Milken Institute; $12504^{\text {th }}$ Street; Santa Monica, CA 90401. Phone: (310) 998-2647. Fax: (310) 998-2625. Email: strimbath@milkeninstitute.org

Forthcoming in Managerial Finance, special issue on Strategic Finance. 


\section{Financial Buyers in Takeovers: Focus on Cost Efficiency}

\section{Introduction}

Hostile takeovers came under fire in the U.S. around the end of the 1980s. What seems to have particularly galvanized public opinion are the aggressive tactics of financial investors. The active financial investors that purchased operating companies were dubbed "corporate raiders" and were also subject to congressional actions. ${ }^{1}$ Business professionals seeking advantages through changes in corporate control were portrayed as "slick Gordon Geckos, destroyers of wealth" or worse. ${ }^{2}$

The purpose of this paper is to examine whether financial buyers are more likely to initiate takeovers of inefficient firms. ${ }^{3}$ We show that they indeed are and thus conclude that takeovers by financial buyers play a potentially beneficial role in the allocation of corporate assets in the U.S. economy.

Our analysis of determinants of takeovers initiated by financial buyers uses an application of the methodology developed in Trimbath, Frydman and Frydman (2001) (hereinafter referred to as TFF). As a significant improvement over the earlier approaches that have utilized probit and logit analysis, our methodology employs the Cox regression model, which is particularly appropriate for the study of a time-varying risk profile. The Cox model is a dynamic technique that incorporates time-dependent covariates and estimates the hazard rate of takeover at any time during the study period as a function of

\footnotetext{
${ }^{1}$ Including consideration of the "Corporate Raiders Tax Act of 1987."

2 "Method to the Merger Madness: Revisiting the '80s takeover boom," Dale Oesterle, Regulation (Cato Institute, 1997), 20(2). Gordon Gekko is the villain/hero of Oliver Stone's 1987 film "Wall Street." See Pound (1992) for more on perceptions about "raiders".

${ }^{3}$ We distinguish financial buyers from what is typically referred to as "LBO associations." Financial buyers do not necessarily require debt financing to purchase operating firms. Furthermore, many studies of LBOs mix management buyouts with the merger of operating companies on the basis of commonality in the use of leverage.
} 
these covariates. ${ }^{4}$ Using this methodology we show that the most significant determinant of a firm's risk of takeover by a financial buyer is its relatively inefficient use of resources. $^{5}$

The focus on financial buyers also allows a particularly clear look at the efficiency enhancement, if any, of their targets. Financial buyers often take the target firm public a second time. This affords us the opportunity to study an exact "before and after" picture of the target firm without the complications necessary to break out the performance of a division (when the target is merged into another operating company). In our sample, of the 38 firms taken over by financial buyers since 1981, we were able to identify 19 as having been reissued to the public. ${ }^{6}$ Among identifiable individual financial buyers active in taking over Fortune 500 firms in our sample, Kohlberg, Kravis and Roberts (8) and Forstmann Little and Company (5) were the most active.

In order to illustrate efficiency enhancements introduced by financial buyers, we select Forstmann and Little's acquisition of General Instrument for a brief case study. We show that Fortsmann and Little's aggressive programs of cost management substantially improved the efficiency of General Instrument. Moreover, it allowed General Instrument to expand research and development to become the global leader in high definition television.

The structure of the paper is as follows. In Section II we descibe the data and discuss some descriptive statistics. In Section III we describe briefly the Cox regression

\footnotetext{
${ }^{4}$ See Section III of this paper for a brief overview of the Cox regression model.

${ }^{5}$ These results are consistent with the results obtained in TFF for the Fortune 500 firms.

${ }^{6}$ In fact, we were able to identify all but 4 as companies still in operation. The 15 not taken public continue to operate as private subsidiaries of the financial parents (holding companies).
} 
model. Sections IV and V present the results and our case study. Finally, Section VI contains concluding remarks.

\section{Data Description}

This study, similar to TFF, is based on a sample of U.S. corporations included in the Fortune 500 ranking at least one year between 1980 and 2001. The following describes the sample and the construction of data observations applicable to our analysis. Except for the extension into 2001, this is the same sample as used in TFF. Therefore, the reader is referred to TFF for details. We repeat here only the most relevant portions of the sample and data description.

\section{Sample and Data Description}

Takeovers - defined as a transaction in which a complete change of ownership occurs - were tracked each year from 1981 through $2000 .^{7}$ All performance data are taken from the Compustat files with missing observations completed from Moody's Industrial Manuals and SEC reports. Each firm was assigned to one of six sectors based on its industry: basic resources, cyclical consumer products, non-cyclical consumer products, energy, industrial, and technology. The sectors follow the definitions used in the Dow Jones Stoxx Index and are used to control for sector-specific effects on firm performance and the risk of takeover. ${ }^{8}$

In this paper, we focus on the effects of cost efficiency on the risk of takeover by active financial investors. Cost per unit of revenue is measured as [(cost of goods sold

\footnotetext{
${ }^{7}$ The study examined every firm in the sample to determine if that firm was involved in a takeover rather than relying on one listing of takeovers. The first source was the deletions list provided in Fortune's annual issue. This information was supplemented with Mergers \& Acquisitions Almanac, CCH Capital Changes Reporter, Moody's Industrial and Transportation Manuals (corporate history), Hoover's Corporate Profiles and the footnotes and deletion codes to Compustat.

${ }^{8}$ There were no takeovers by financial buyers in the Energy sector in our sample. Therefore, the models only control for five sectors.
} 
plus selling, general and administrative expenses) divided by (net sales)]. To gauge the performance of a firm relative to similar firms, our study adjusts each measure of performance by subtracting the annual sample median.

Some earlier corporate takeover studies interpreted cost per unit of revenue as a proxy for cash flow or profitability. ${ }^{9}$ However, cost efficiency may provide a relatively reliable measure of the prospective gain from post-takeover cost restructuring of a target. Therefore, the adjusted cost per unit of revenue may be an important determinant of the risk of takeover and it should not be necessarily considered as just a proxy for profitability. $^{10}$

We also test net profit (net income divided by total assets). In addition to these performance measures, we used revenue (net sales) in constant dollars as a measure of the size of firms. Beyond controlling for firm size, the deflated revenue variable also provides information, complementary to the cost per unit of revenue, on the potential gains from a takeover of a relatively inefficient target. Earlier studies often interpreted the significance of the size variable in relation to capital market constraints. ${ }^{11}$ Both of these interpretations motivate our use of the unadjusted, rather than adjusted, size variable in our hazard models. ${ }^{12}$

\footnotetext{
${ }^{9}$ For example Ravenscraft and Scherer (1987) used the equivalent of 1 minus (cost per unit of revenue) as a proxy for profitability.

${ }^{10}$ We suggested earlier (Trimbath, Frydman and Frydman (2000)) that a shortfall in profitability may signal the inefficient use of resources, though such a shortfall is likely to be a relatively more uncertain measure of the potential for gain from a takeover. Net profit rate, operating profit rate, labor productivity and a proxy for Tobin's q were also investigated using this sample (with data through 1996) and methodology. None produced temporally stable results or were significant in a model that included costs. The same was true in regressions using shareholder returns and labor productivity as determinants of risk (Trimbath (2002)). See Pugh and Jahera (1995) for more on shareholder returns.

${ }^{11}$ See TFF for a more detailed discussion of the role of size for the risk of takeover.

${ }^{12}$ Estimation results for hazard models using industry-adjusted size variables are very similar to the results reported here. For a detailed analysis of such models, see Trimbath (2002). Adjusted and unadjusted size variables were highly correlated (the correlation coefficient is 0.999 ).
} 


\section{Descriptive Statistics}

We identified 38 targets as being taken over by financial buyers. ${ }^{13}$ The category of financial buyers includes investment bankers (e.g., Merrill Lynch, Shearson Lehman, Kohlberg, Kravis and Roberts) plus private investors (e.g. Rupert Murdoch, Carl Icahn). ${ }^{14}$ In our sample over $80 \%$ of the financial buyer takeovers were completed before $1990 .{ }^{15}$ The low number of financial buyers after 1990 makes comparisons across time problematic. For that reason, descriptive statistics are presented for the full sample period (1980-1999 observations; 1981-2000 takeovers). Median performance measures for targets of financial buyers and all other firms are presented in Table 1. The targets of financial buyers have significantly higher costs and lower profits than other firms. Thus, financial buyers appear to initiate takeovers of highly inefficient firms. In Section IV we will check whether this conclusion holds in the context of the multivariate Cox regression model.

\footnotetext{
${ }^{13}$ Targets of other buyers in our sample include 186 targets of other corporate entities, 18 targets of employees and 74 targets of foreign-owned firms.

${ }^{14}$ If employees were assisted by an investment bank, the buyer is considered to be a financial firm if the investment bank owns more than $50 \%$ of shares ex post.

${ }^{15}$ For the argument that this is due to regulatory changes concerning financing of takeovers see TFF and Trimbath (2002). Fields (1996) introduces a special issue of Managerial Finance on the topic of finance and the regulatory environment.
} 
Table 1 Relative Performance of Targets of Financial Buyers

\section{Targets of Targets of Non-Financial \\ Financial Buyers Buyers or Non-Targets}

\begin{tabular}{lrr}
\hline Costs/sales & 0.0120 & $\boldsymbol{- 0 . 0 0 0 7}$ \\
Net profit (\%) & -2.080 & $\mathbf{0 . 0 2 7 ^ { * * }}$ \\
Assets (\$) & 572 & $\mathbf{9 1 7}^{\text {***}}$ \\
Sales $(\$)$ & 725 & $\mathbf{1 1 2 0 ^ { * * }}$ \\
$\mathrm{N}$ & 38 & 808 \\
\hline
\end{tabular}

Bold if significantly different from targets of financial buyers: $* * * p<0.01, * * p<0.05$. Table entries are the average of annual medians, adjusted for the sample median in each year of observation. Size (assets and sales) are unadjusted, in constant 1980 dollars. 
Mørck, Shleifer and Vishny (1988) have hypothesized that only hostile takeovers are motivated by efficiency considerations. This would suggest that classifying targets by buyer type, as we do here with respect to financial buyers, might involve heterogeneous motivations and obscure the results. To check this, we examined additional evidence concerning the "hostility" of takeovers. We found that financial buyers are not more likely to institute management changes ex post than other buyer types. ${ }^{16}$ In our sample, financial buyers are not significantly more likely to have their offer rejected (18\%) nor are they more likely to change the target managers (41\%) than other buyers. Therefore, this evidence does not support separate theories or regulations for "hostile raiders."

\section{The Cox Regression Model}

This paper employs the hazard regression model proposed by Cox (1972) as its statistical model. The Cox regression model offers a powerful tool for modeling the dependence of the risk of takeover on a firm's characteristics, and of the evolution of that risk over time. Here we briefly present the Cox model and highlight those aspects of the model estimation which are most relevant to the current study. For a more extensive exposition of the Cox model, the reader is referred to TFF. The TFF paper also contains a discussion of the features of the Cox model which make it particularly suitable for studying the variation of takeover risk over time. (An exhaustive discussion of the Cox regression model may also be found in Kalbfleisch and Prentice (1980), Fleming and Harrington (1991), and Andersen and Louis (1995).)

The conditional hazard function of a takeover (say by a financial buyer), $\lambda\left(t \mid X_{i}(t)\right.$ ), of the $i$ 'th firm with the covariate vector $X_{i}(t)$, is defined by

\footnotetext{
${ }^{16}$ The result is similar to that reported in Walsh and Kosnick (1993).
} 


$$
\lambda\left(t \mid X_{i}(t)\right)=\lim _{\Delta t \rightarrow 0} P\left(T_{i}<t+\Delta t \mid T_{i} \geq t, X_{i}(t)\right) / \Delta t .
$$

It is seen from (1) that for small $\Delta t$

$$
\lambda\left(t \mid X_{i}(t)\right) \Delta t \approx P\left(T_{i}<t+\Delta t \mid T_{i} \geq t, X_{i}(t)\right)
$$

and thus $\lambda\left(t \mid X_{i}(t)\right)$ is approximately the probability that a firm experiences a takeover just after time $t$ given survival until time $t$ and given the covariates $X_{i}(t)$. The Cox hazard regression model specifies the following form for the conditional hazard function

$$
\lambda\left(t \mid X_{i}(t)\right)=\lambda_{0}(t) \exp \left(\beta^{\prime} X_{i}(t)\right)
$$

where $\beta^{\prime}=\left(\beta_{1}, \ldots, \beta_{k}\right)$ is a vector of unknown regression coefficients, $\lambda_{0}(t)$ is an unknown and unspecified baseline hazard function, and $\beta^{\prime} X_{i}(t)$ is an inner product. The $X_{i}(t)$ may be simply the value of the firm's covariates at time $t$ or any suitable function of the history of the firm's covariates up until time $t$.

An important aspect of the Cox model is that, at any point in time, the ratio of the hazard rates of takeover for two different firms does not involve the baseline hazard function. Consequently, in the case of time independent covariates, the ratio of hazard rates stays constant over time. For this reason, the Cox regression model is often referred to as the proportional hazards model. The parameter $\exp \left(\beta_{p}\right)$ represents a relative change in the hazard rate resulting from a one unit increase in the value of the $p$ 'th covariate, holding all other covariates constant, namely

$$
\exp \left(\beta_{p}\right)=\frac{\exp \left[\beta_{p}\left(X^{p}+1\right)\right]}{\exp \left[\beta_{p}\left(X^{p}\right)\right]}
$$

The baseline hazard function, $\lambda_{0}(t)$, gives the hazard rate for a firm with covariates equal to 0 . Since we use the cyclical consumer products sector as a baseline and we do not 
adjust the size variable, $\lambda_{0}(t) \exp \left(\beta_{\text {size }}\right.$ Size $)$ represents the hazard rate of a takeover faced by a firm in the cyclical consumer products sector of a given size, performing at the sample medians for all other performance measures.

The parameters of the Cox regression model are $\lambda_{0}(t)$ and the regression coefficients $\beta$. Cox (1972) proposed the partial likelihood method for the estimation of $\beta$. The essential feature of the estimation method proposed by Cox (1972) (so called method of partial likelihood) is that it does not involve the baseline hazard function $\lambda_{0}(t)$, that is, parameter $\beta$ can be estimated in the absence of knowledge of $\lambda_{0}(t)$. The baseline hazard function is estimated subsequently in a nonparametric fashion. Since our interest is in the estimation of the relative risk of takeover faced by the firms, we focus on the estimation of $\beta$.

\section{Takeover Data and Estimation}

For takeover data, we do not observe the takeover times for all firms and, furthermore, some firms may not be observed from the beginning of the study. Thus, for the $i$ 'th firm the observed data consist of the entry time $V_{i} \geq 0$, exit time, $\min \left(T_{i}, T\right)$, which is either a takeover time $T_{i}$, or the end of study time, $T$, whichever is smaller, and the covariate history $\left\{X_{i}^{*}(t), V_{i} \leq t<\min \left(T_{i}, T\right)\right\}$. Let $T_{(1)}<T_{(2)}<\ldots<T_{(L)}$ denote ordered observed takeover times. Due to the nature of our data (yearly observations) all times are expressed in years. Let $(k)$ be the label for a firm experiencing a takeover at $T_{(\mathrm{k})}$, so the covariate history associated with label $(k)$ is $\left\{X_{(k)}^{*}(t), V_{(k)} \leq t<\min \left(T_{(k)}, T\right)\right\}$. Let $d_{k}$ be the number of takeovers at $T_{(k)}$, and let $D_{k}$ be the set of firms that are taken over at $T_{(k)}$. Also let $R_{k}$ be the set of firms at risk of a takeover just before time $T_{(k)}$, that is, $R_{k}=\{j$ 
$\left.: V_{j}<T_{(k)} \leq T_{j}\right\}$. The regression coefficients, $\beta$, are estimated by the value of $\beta$ which maximizes the (approximate) partial likelihood:

$$
L \widetilde{(\beta)}=\prod_{k=1}^{L} \frac{\exp \left(\beta^{\prime} S_{k}\right)}{\left\{\sum_{j \in R_{k}} \exp \left[\beta^{\prime} X_{j}\left(T_{(k)}\right)\right]\right\}^{d_{k}}}
$$

where $S_{k}=\sum_{j \in D k} X_{j}\left(T_{(k)}\right)$, and $X_{j}\left(T_{(k)}\right)=X_{j}^{*}\left(T_{(k)}-1\right)$, that is, we assume, that the hazard of failure at $T_{(k)}$ depends on the values of covariates at time $T_{(k)}-1$. Note that since performance measures are not available for the year in which a firm experiences a takeover, we use instead the values of performance measures from the year preceding the year of takeover.

The partial likelihood function is formed as the product over all takeover times. The $k^{\prime}$ th factor in this product is in turn a product of $d_{k}$ conditional probabilities; each representing the probability that a given firm in set $D_{k}$ is taken over at $T_{(k)}$ given that the firms in $R_{k}$ are at risk of a takeover.

Since in this study we focus on the characteristics of targets taken over by financial buyers, for our purposes a takeover event occurs only when a takeover is by a financial buyer. Thus, in our application $T_{(1)}<T_{(2)}<\ldots<T_{(L)}$ are the observed takeover times of takeovers by financial buyers only. The observations on the firms which undergo other types of takeovers are treated as right censored at the times of their takeovers. These firms, similar to non-targets, are in the appropriate risk sets in the partial likelihood function and are assumed to exit the sample at their respective takeover times. Thus, for the purpose of the estimation of the regression coefficients in the hazard function of a takeover by a financial buyer, the targets of other than financial buyers are treated similarly to non-targets. 
In our application the Cox regression model is implemented using STATA

(StataCorp. (2001)).

\section{Results}

The results of our estimation of the Cox regression models including the size and cost variables are presented in Table 2. Size is not significant, suggesting that financial buyers have not faced systematic financing impediments in their takeover transactions. It should be noted that prior studies of takeovers have suggested and often found that size has a negative effect on the risk of takeover and this negative effect of size on risk has been attributed to the difficulties in financing larger takeover transactions (for example, see Singh (1975) and Hasbrouck (1985)). ${ }^{17}$

Firms in the Industrial Sector faced a significantly higher risk of takeover from financial firms unless cost inefficiency is included in the model. ${ }^{18}$ Thus, this sectoral effect seems to capture the greater cost inefficiency of targets of financial buyers in that sector. This accords well with the general belief that industrial restructuring was taking place across inefficient industrial firms to make them more competitive.

\footnotetext{
${ }^{17}$ However, see TFF for an argument and results suggesting that the effect of size on the risk of takeovers is more ambiguous.

${ }^{18}$ The Industrial Sector includes air freight and couriers, building materials, containers and packaging, diversified industrials, electric components and equipment, factory equipment, heavy construction, heavy machinery, industrial and commercial services, marine transportation, transportation equipment, and trucking.
} 
Table 2 Size and Cost Inefficiency and the Risk of Takeover by Financial Buyers

Size

Costs

$\begin{array}{rrr}-0.00004 & -0.00003 & -0.00002 \\ (0.00005) & (0.00005) & (0.00004) \\ & & \mathbf{6 . 4 0 4 0}^{* * *}\end{array}$

(1.9401)

Sector Dummy Variables

Basic Resources

$\begin{array}{rr}0.24296 & 0.3670 \\ (0.55833) & (0.5540) \\ 0.53922 & 0.5415 \\ (0.52742) & (0.5261) \\ \mathbf{0 . 8 2 8 9}^{*} & 0.7697 \\ (0.4832) & (0.4854) \\ 0.3815 & 0.5023 \\ (0.6251) & (0.6236)\end{array}$

Chi-Square

0.53

4.78

$19.58^{\star * *}$

degrees of freedom

5

6

*** $\mathrm{p}<0.01,{ }^{* *} \mathrm{p}<0.05,{ }^{*} \mathrm{p}<0.10$. Cyclical Consumer Products is the excluded sector. All regressions use 846 firms and 38 takeovers. Cox proportional hazard models estimated with robust standard errors (Lin and Wei, 1989). Coefficients are the change in the log-odds per unit. 
The results presented in Table 2 show that cost inefficiency appears to be an important determinant of the risk of takeover. To check the robustness of this result and facilitate comparison with earlier takeover studies using measures of profitability, Table 3 reports estimation results for the models including cost and net profit variables.

The results presented in Table 3 suggest that once the cost variable is included in the model, the net profit variable looses significance. ${ }^{19}$ Although the profitability measure is significant in a model excluding the cost variable, this model has significantly lower explanatory power. This can be readily seen by comparing the value of the chi-squared statistics in models with and without costs.

\footnotetext{
${ }^{19}$ In TFF we show that this result holds for operating profit and other performance measures in a model of determinants of Fortune 500 targets that ignores the buyer type.
} 
Table 3 Cost and Net Profit and Risk of Takeover by Financial Buyers

$\begin{array}{lrc}\text { Size } & -0.00003 & -0.00002 \\ & (0.00005) & (0.00004) \\ \text { Costs } & & \mathbf{4 . 8 9 4 7 5 ^ { * * }} \\ & & (2.20541) \\ \text { Net Profit } & -\mathbf{0 . 0 3 9 5} 5^{* * *} & -0.02446 \\ & (0.0147) & (0.02227)\end{array}$

Sales/Assets

Sector Dummy Variables

$\begin{array}{lrr}\text { Basic Resources } & 0.2293 & 0.31604 \\ \text { Non-Cyclical Consumer Products } & (0.5566) & (0.55151) \\ & 0.6500 & 0.6022 \\ \text { Industrial } & (0.5350) & (0.5351) \\ & \mathbf{0 . 8 0 9 4}^{*} & 0.7637 \\ \text { Technology } & (0.4832) & (0.4859) \\ & 0.4093 & 0.4744 \\ & (0.6225) & (0.6302) \\ \text { Chi-Square } & & \\ \text { degrees of freedom } & \mathbf{1 2 . 4 8}^{*} & \mathbf{2 3 . 2 3}^{\text {***}} \\ \text { (2) } & 6 & 7\end{array}$

degrees of freedom 7

$* * * \mathrm{p}<0.01,{ }^{* *} \mathrm{p}<0.05, * \mathrm{p}<0.10$. Cyclical Consumer Products is the excluded sector. All regressions use 846 firms and 38 takeovers. Cox proportional hazard models estimated with robust standard errors (Lin and Wei, 1989). Coefficients are the change in the log-odds per unit. 


\section{CASE STUDY: General Instrument Corporation}

Before the takeover, General Instrument Corporation was known as a "middlingmuddling conglomerate." When Fortsmann Little and Company was considering the acquisition, General Instrument was a mixed bag of defense electronics, pari-mutuel wagering systems, telecommunications gear (cable boxes), cable for cable TV systems, and scramblers of satellite TV signals. By the time General Instrument went public again, it was focused solely on supplying materials and technology to the cable and satellite television industries. General Instrument was resold to the public in 1992 for nearly three times a share what Fortsmann Little had paid. By the spring of 1994 the firm's investors had realized more than $\$ 1.6$ billion in cash and stock value for their investment of $\$ 202$ million in equity.

\section{Background}

Founded in 1923 in New York City as a simple machine shop, General Instrument Corporation (GI) went public for the first time in 1939 with an offering on the New York Stock Exchange. Over the next forty years, GI would expand into such diverse fields as phonographs and munitions. With the 1986 acquisition of the Videocipher encryption system, GI achieved a near monopoly in the newly developing market for de-scramblers for home satellite dishes.

Founded in 1978, Forstmann Little and Company (FL) claimed to have achieved an average compounded annual return of 85 percent for equity-fund partners and 33 percent for subordinated-debt partners during the 1980s. FL developed a reputation for paying reasonable prices for mature businesses in stable industries with steady cash flows and a dominant position. By 1991, however, FL had adopted a riskier, more aggressive 
strategy. The acquisition of GI, for example, took place in a recessionary year and involved a technology enterprise with growth prospects but the need for major investment in research and technology. FL also was able to finance acquisitions with less debt and more equity than they had used during the 1980 s. $^{20}$

\section{Acquisition}

FL's $\$ 44.50$ a share ( $\$ 1.6$ billion) tender offer acquisition of GI was completed on August 23, 1990. Less than two months later, on October 5, 1990, FL named Donald H. Rumsfeld chairman and chief executive officer of GI.

\section{Efficiency Enhancements}

Rumsfeld was no stranger to corporate turnarounds. After serving as defense secretary and chief of staff to President Gerald Ford, Rumsfeld helped turn around G.D. Searle \& Co. before its purchase by Monsanto Co. His strategy for GI was to concentrate on the basic business, sell off assets "that don't fit," cut costs and reduce debt. Eventually, GI shed businesses with annual sales of nearly $\$ 400$ million (Table 4).

Revenues fell an additional $14 \%$ in the first ex post year as cable TV companies cut back capital spending during the early 1990 s credit crunch. $^{21}$ That jeopardized the cash flow GI needed to meet loan covenants with its banks. Rumsfeld cut $\$ 65$ million in annual overhead, mostly by shedding staff and management layers. GI cut inventories; to cut inefficiency, it instituted crash quality-control programs in its factories. ${ }^{22}$ In addition to meeting financial goals, the cost reduction allowed GI to increase R\&D spending by a

\footnotetext{
${ }^{20}$ In fact, FL's $\$ 285$ million purchase of Department 56, Inc. in 1992, made without any bank financing, is reported to have been the first self-financed transaction in the history of leveraged buyouts.

${ }^{21}$ The Federal Reserve Board designated the borrowings of cable companies as "highly leveraged transactions." The clamp down on bank lending in high-debt situations, and its impact on the supply of capital equipment funding, produced the toughest credit crunch the cable industry had ever experienced. ("Deal of the decade," Jacqueline S. Gold, Financial World, Sept 1, 1992, p26(4).)

22 "How a high-tech bet paid off big," Thomas A. Stewart, Fortune, Nov 1, 1993, p. 101(2).
} 
third, enabling them to stay ahead of the curve on video compression and high definition television (HDTV) development. ${ }^{23}$ From the year before the takeover to the year after, GI's revenues fell by 39.8 percent while cost of goods sold fell 43.0 percent. The cost per unit of revenue, however, fell less than 1 percent during the same period because selling, general and administrative expenses, which include R\&D spending, fell more slowly at 31.8 percent. As cable industry spending began to recover the following year (1992), GI's costs rose only 33.0 percent while revenue grew more quickly at 36.9 percent, resulting in improvement in cost per unit of revenue. ${ }^{24}$

\section{Ex Post}

On June 22, 1992, FL sold 22 million shares of GI at $\$ 15$ a share for $\$ 330$ million, making it a public company once again. On February 3, 1993 FL sold an additional 8.6 million at $\$ 30.50$ in a move to pay off its debt early and to reduce its interest expenses. On September 30, 1993, FL sold just over five million shares of stock in GI for \$51 each. Before underwriters' fees, the buyout partners had realized almost $\$ 850$ million - and still owned 19.3 million shares. In April 1995, FL sold additional shares at \$40 each. The final 15 percent was sold in April 1999 for $\$ 650$ million. ${ }^{25}$ In total, FL earned $\$ 2.155$ billion between August 1990 and April 1999 for their \$202 million equity investment in GI - a nominal annual rate of return of 98 percent.

\footnotetext{
${ }^{23}$ Improved financial performance is not atypical in such cases. Holthausen and Larcker (1996) find enhanced financial performance in a study of reverse leverage buyouts using industry-adjusted performance. However, they report reduced R\&D spending, unlike in the case of GI.

${ }^{24}$ Cost of goods sold and SG\&A rose by 35.1 and 26.0 percent, respectively.

${ }^{25}$ In May 1997, GI split into three independent companies. NextLevel Systems, which specialized in system networks, changed its name back to General Instrument in 1998 and was acquired by Motorola in 1999 for $\$ 17$ billion. The purchase gave Motorola 59 percent of the $\$ 1.9$ billion worldwide digital set-top box market. (“Cable Set-top Box Makers Go Digital - Big Time," Mike Paxton, Electronic News (1991), Nov 27, 2000, p14.)). General Semiconductor was acquired by Vishay Intertechnology in 2001. CommScope, which specializes in cable television services, continues to operate as an independent company.
} 
Table 4 General Instrument Before and After 1990 Acquisition

\begin{tabular}{rrrrrrrr}
\hline Sales & $1,155.46$ & $1,304.73$ & $1,377.34$ & 785.14 & $1,074.70$ & $1,392.52$ & $2,036.32$ \\
$\begin{array}{r}\text { Cost of Goods Sold } \\
\text { Selling, General }\end{array}$ & 784.70 & 875.48 & 914.98 & 498.61 & 673.76 & 884.42 & $1,331.81$ \\
$\begin{array}{r}\text { and Administrative } \\
\text { Expenses }\end{array}$ & 192.06 & 219.56 & 218.32 & 149.67 & 188.58 & 217.10 & 291.09 \\
$\begin{array}{r}\text { Cost per unit of } \\
\text { revenue }\end{array}$ & 0.845 & 0.839 & 0.823 & 0.826 & 0.802 & 0.791 & 0.797 \\
Net Profit (\%) & 6.1 & 6.5 & 7.5 & -5.3 & -2.4 & 5.1 & 11.8 \\
\hline
\end{tabular}

Cost per unit of revenue is the ratio of cost of goods sold and selling, general and administrative expenses to sales. Sales, Cost of Goods Sold and Selling, General and Administrative Expenses in \$millions. Profit is net income as a percent of assets. 


\section{CONCLUDING REMARKS}

Despite their vilification in the 1980s, we show that the active financial investors that purchased operating companies were more likely to initiate takeovers of inefficient firms. We thus conclude that takeovers by financial buyers play a potentially beneficial role in the allocation of corporate assets in the U.S. economy. 


\section{REFERENCES}

Anderson, Jon E. and Thomas A. Louis (1995). "Survival analysis using a scale change random effects model," Journal of the American Statistical Association, 90 (430), p.669-679.

Cox, D.R. (1972). "Regression Models and Life-Tables,” Journal of the Royal Statistical Society, Series B, 34, p. 187-220.

Fields, M. Andrew (1996). "Finance and the Regulatory Environment - an introduction," Managerial Finance, 22(7), p.1-7.

Fleming, T. R., and D. P. Harrington (1991). Counting Processes and Survival Analysis (Wiley, New York, NY).

Hasbrouck, Joel (1985). “The Characteristics of Takeover Targets: Q and Other Measures," Journal of Banking and Finance, 9, p. 351-362.

Holthausen, Robert W., and David F. Larcker. 1996. "The Financial Performance of Reverse Leveraged Buyouts,” Journal of Financial Economics 42/3 (November): pp. 293-332.

Kalbfleisch, J.D. and R.L. Prentice (1980). The Statistical Analysis of Failure Time Date, John Wiley \& Sons, New York.

Lin, DY and LJ Wei (1989). “The Robust Inference for the Cox Proportional Hazards Model," Journal of the American Statistical Association, 84 (408), p. 1074-1078.

Mørck, Randall, Andrei Shleifer, and Robert W. Vishny. (1988). "Characteristics of Targets of Hostile and Friendly Takeovers," in Auerbach, Alan J., ed. (1988), 
Corporate Takeovers: Causes and Consequences, University of Chicago Press, Chicago.

Pound, John (1992). "Raiders, targets, and politics: The history and future of American corporate control," Journal of Applied Corporate Finance, 5, p. 6 - 18.

Pugh, William N. and John S. Jahera Jr. (1995). "Evidence of market overreaction to state antitakeover legislation," Managerial Finance, 21 (5), p52-66.

Ravenscraft, David J. and F.M. Scherer. (1987). Mergers, Sell-Offs, and Economic Efficiency, Brookings Institution, Washington, D.C.

Singh, Ajit (1975). "Take-Overs, Economic Natural Selection, and the Theory of the Firm: Evidence from the Postwar United Kingdom Experience," The Economic Journal, 85, p. 497-515.

StataCorporation (2001). Stata Statistical Software: Release 7.0. College Station, TX: Stata Corporation.

Trimbath, Susanne, Halina Frydman and Roman Frydman (2000). "Corporate Inefficiency and the Risk of Takeover," Stern School of Business, Department of Finance Working Paper FIN-00-061.

Trimbath, Susanne, Halina Frydman, and Roman Frydman (TFF, 2001). “Cost Inefficiency, Size of Firms and Takeovers," Review of Quantitative Finance and Accounting, 17(4), p. 397-420.

Trimbath, Susanne (2002). Mergers and Efficiency: Changes Across Time, Kluwer Academic Press. 
Walsh, James P. and Rita D. Kosnik. (1993). "Corporate Raiders and Their Disciplinary Role in the Market for Corporate Control," Academy of Management Journal, 36(4), p. 671-700. 